\title{
17. A MAGNETIC LOGGING STUDY OF HOLE 735B GABBROS AT THE SOUTHWEST INDIAN RIDGE ${ }^{1}$
}

\author{
Janet E. Pariso, ${ }^{2}$ James H. Scott,${ }^{3}$ Eiichi Kikawa,${ }^{4}$ and H. Paul Johnson ${ }^{2}$
}

\begin{abstract}
Borehole measurements of magnetic field and magnetic susceptibility were performed in Hole 735B near the Southwest Indian Ridge and represent the first determination of in-situ magnetic properties of oceanic gabbros. Five of the six lithologic units described by the shipboard scientists are clearly distinguished on the basis of variations in magnetic logs. The bulk of the olivine gabbros penetrated during Leg 118 have an average $J_{0}$ of $1.7 \mathrm{~A} / \mathrm{m}$ and $Q$ ratios greater than 1, indicating that gabbroic rocks may be important contributors to marine magnetic anomalies. An average in-situ $J_{0}$ value of $9 \mathrm{~A} / \mathrm{m}$ was estimated for the iron- and titanium-rich gabbros from the logging data because the recovered drill core was observed to have acquired a large component of secondary magnetization (drilling remanence). Analyses of the downhole magnetic and discrete sample data show that the Hole 735B crustal section has a single coherent direction of stable magnetization (reversed) and that no relative rotation within the drilled section took place below $580^{\circ} \mathrm{C}$. Two-dimensional magnetic modeling using the above results indicates that layer 3 gabbros can contribute from $20 \%$ to $56 \%$ to linear marine magnetic anomalies.
\end{abstract}

\section{INTRODUCTION}

The Vine-Matthews model (1963) of the formation of linear marine magnetic anomalies formed a strong basis for models of seafloor spreading and, subsequently, the theory of plate tectonics. However, despite extensive study of marine magnetic anomalies and magnetic properties of igneous rocks from the seafloor, the source layer for these magnetic anomalies is still somewhat ambiguous. While a thin $(\sim 0.5 \mathrm{~km})$ layer of highly magnetized basalt has been shown to be sufficient to account for the amplitude of observed magnetic anomalies (Talwani et al., 1971; Atwater and Mudie, 1973; Klitgord et al., 1975), direct sampling of off-axis basalts and basalt samples recovered during the Deep Sea Drilling Project showed that (1) the average magnetization was usually less than that required by inversion of magnetic anomaly data and (2) multiple magnetic polarities were often present in a single vertical crustal section (Lowrie, 1974; Hall and Ryall, 1977; Johnson and Atwater, 1977; Johnson and Merrill, 1978). Although many studies suggested that lower oceanic crust might be an important contributor to marine magnetic anomalies (Blakely, 1976; Kent et al., 1978; Dunlop and Prevot, 1982; Smith and Banerjee, 1986), our ability to examine these lower crustal layers has been hampered by the difficulty in obtaining samples from this portion of oceanic crust. Until recently, continuous drilling, which provides vertically oriented samples, had only a single penetration as deep as the sheeted dike complex, Hole 504B (Becker et al., 1989). Our direct magnetic measurements of oceanic layer 3 thus were restricted to unoriented samples dredged from fracture zones (Fox and Opdyke, 1973; Kent et al., 1978) and samples from high level, intermittent intrusives from DSDP drill cores (Dunlop and Prevot, 1982; Smith and Banerjee, 1985). In addition, gabbros from ophiolite complexes have been studied

\footnotetext{
${ }^{1}$ Von Herzen, R. P., Robinson, P. T., et al., 1991. Proc. ODP, Sci. Results, 118: College Station, TX U.S.A. (Ocean Drilling Program).

2 School of Oceanography, University of Washington, Seattle, WA 98195.

312372 West Louisiana Avenue, Lakewood, CO 80228.

${ }^{4}$ Marine Geology Department, Geological Survey of Japan, Tsukuba 305 , Japan.
}

as an analog for oceanic crust (Pariso and Johnson, 1989; Swift and Johnson, 1984; Banerjee, 1980). Although many of these studies suggested that gabbros were, under some circumstances, capable of contributing to marine magnetic anomalies, the large observed variation in degree and type of alteration, and the corresponding large variation in magnetic properties, made it difficult to generalize about the magnetic properties of oceanic gabbros.

Drilling during Leg 118 penetrated $500.5 \mathrm{~m}$ into a shoal platform adjacent to the Atlantis II Fracture Zone on the Southwest Indian Ridge and recovered the first continuous, vertically oriented suite of plutonic rocks from the oceanic crust. This represents a unique opportunity to examine, for the first time, the in-situ magnetic properties of oceanic gabbros and to also examine the potential of layer 3 to contribute to marine magnetic anomalies.

Borehole measurements of magnetic field and magnetic susceptibility were performed during Leg 118 (1) to examine the intensity, direction, and coherence of the remanent magnetization within the drilled section and (2) to provide a high-resolution record of the variations of these magnetic parameters as a function of lithology and degree of alteration. Because drilling during Leg 118 resulted in an unusually high recovery rate of drill core, the recovered rocks represent an excellent type section with which to "ground-truth" magnetic logging techniques by comparing these with magnetic properties measurements performed using discrete samples.

It is important to compare the magnetic properties of discrete samples taken from the recovered drill core with logging data for several reasons. Magnetic logging data provide a much higher resolution record of magnetic field and magnetic susceptibility (one measurement per 10 and $30 \mathrm{~cm}$, respectively, vs. one measurement per $2.8 \mathrm{~m}$ for minicore data in this study). Logging also returns relatively unbiased samples of the crustal section compared to minicores, which are selected individually from sections of the drill core, and may represent only a small percentage of the drilled section that is recovered. Leg 118 was unusual in that recovery rates were high $(87 \%$ overall and $95 \%$ for the lower $350 \mathrm{~m})$. Although all the Hole 735B cores provide a good representation of the penetrated lithologies, minicores represent a small percentage 
of those cores and may be subject to sampling bias (although one should try to select representative minicores). In addition, many of the Hole 735B samples may have acquired a large component of secondary magnetization from drilling. Because logs are measured in-situ, downhole magnetic data can be used to estimate the true $J_{0}$ of these samples.

On the other hand, interpretation of downhole magnetic data is plagued by "uniqueness" problems inherent in most indirect geophysical measurements. Minicore data provide important constraints on both determination of magnetic intensity and direction from logging data. This study focuses on the analyses of downhole magnetic logs and presents measurements of magnetic properties for minicores, primarily as a means of calibrating these logging data and of constraining our interpretations. For a more in depth view of these discrete sample measurements, the reader is referred to Kikawa and Pariso (this volume).

\section{EQUIPMENT AND EXPERIMENTAL METHODS}

Downhole magnetic measurements presented here were performed with three separate tools: a combination threecomponent magnetometer and susceptibility tool developed at the University of Washington (UW), a U.S. Geological Survey (USGS) three-component magnetometer with gyro and inclinometer orientation, and a USGS susceptibility probe. The UW combination tool and the USGS magnetometer were centralized in the $25-\mathrm{cm}$-diameter borehole using three-arm bowstring centralizers. The USGS susceptibility tool was not centralized and is presumed to have been side-walled by gravity. The design and operation of these tools is described in more detail in the Proceedings for the Ocean Drilling Program, Initial Reports, Vol. 118, and the reader is referred to this source for any information not covered here.

Magnetic susceptibility was measured using both USGS and UW sensing coils. Unfortunately, the UW susceptibility coil was tuned for lower sensitivity measurements. Thus, we present only data from the USGS tool. Both the USGS and UW three-axis magnetometers provide a measurement of the total magnetic field within the borehole by combining measurements performed in three orthogonal directions. The USGS tool has the additional advantage of an independent gyro-orientation system, which is calibrated and referenced to magnetic north at sea surface and to the vertical using two inclinometers. Thus, magnetic data from the USGS tool can be analyzed separately as three independent components (vertical, north-south, and east-west). Measurements performed with the UW tool are oriented only with respect to vertical (which is assumed to be parallel to the borehole) and thus may be analyzed as two components only (vertical and horizontal).

The magnetic field measured in a borehole has contributions from three sources: (1) Earth's magnetic field, which is commonly the largest component; (2) the field produced by natural remanent magnetization $\left(J_{0}\right)$ of the rock surrounding the borehole; and ( 3 ) the field produced by magnetization $(J$ $=\chi \cdot H)$, which is induced in the formation by Earth's magnetic field. The magnitude of Earth's magnetic field at Site 735 was measured before and after drilling with a proton-precession magnetometer towed behind the JOIDES Resolution. From this instrument, the intensity of Earth's magnetic field was estimated as $37,250 \mathrm{nT}( \pm 50 \mathrm{nT})$. Magnetic inclination and declination were estimated as $-61^{\circ}$ and $35^{\circ} \mathrm{W}$, respectively, from 1985 IGRF charts. Using these values, the individual components of Earth's magnetic field were determined. For most of our discussion, the examination of the total magnetic field is adequate. However, in some instances, it was necessary to examine the vertical anomaly field. We calculated this by subtracting the vertical component of Earth's magnetic field from that measured in the borehole.

\section{RESULTS}

\section{Magnetic Structure and Lithology}

Magnetic properties of igneous rocks, among other parameters, are strongly dependent on changes in grain size and concentration of magnetic minerals. Because these parameters are controlled directly by variations in geochemistry, cooling, and degree of alteration, one can use magnetic logs, under certain circumstances, as maps of variations in these parameters. On the largest scale, the overall character of the magnetic logs allows one to use changes in mean value and peak-to-peak signal amplitude to define separate magnetic zones within Hole 735B. These magnetic zones agree well with most of the individual lithologic units described by the Leg 118 Shipboard Scientific Party (see Fig. 1). Thus, we chose to present magnetic logging data (total magnetic field and magnetic susceptibility) together with discrete sample data (intensity of natural remanent magnetization, $J_{0}$, and magnetic susceptibility, $\chi$ ) on a unit by unit basis. We follow this with (1) a comparison of borehole vs. laboratory measurements, (2) an analysis of the directional data acquired down-

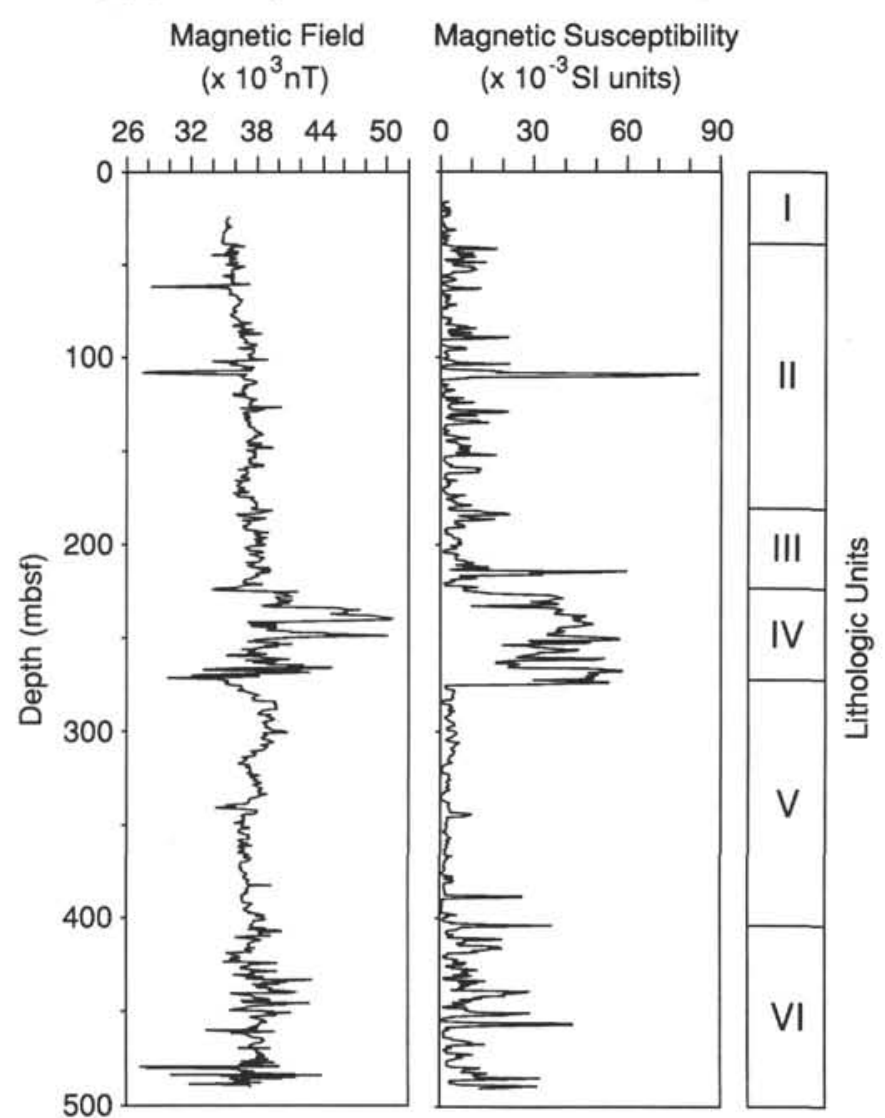

Figure 1. Plots of downhole measurements of total magnetic field and magnetic susceptibility vs. depth and lithology. Lithologic units are as follows: $\mathrm{I}=$ foliated metagabbros, $\mathrm{II}=$ olivine and olivine-bearing gabbro, III = olivine gabbro with intervals of iron and titanium oxide-rich gabbro, IV = iron and titanium oxide-rich gabbro, V = olivine gabbro, and VI= olivine-rich gabbros with intervals of troctolite and iron and titanium oxide-rich gabbro. With the exception of the Unit II/Unit III boundary, the boundaries of the defined lithologic units agree well with changes in mean value and peak-to-peak signal amplitude of both logs. 


\section{Downhole Magnetic Field}

(nT)

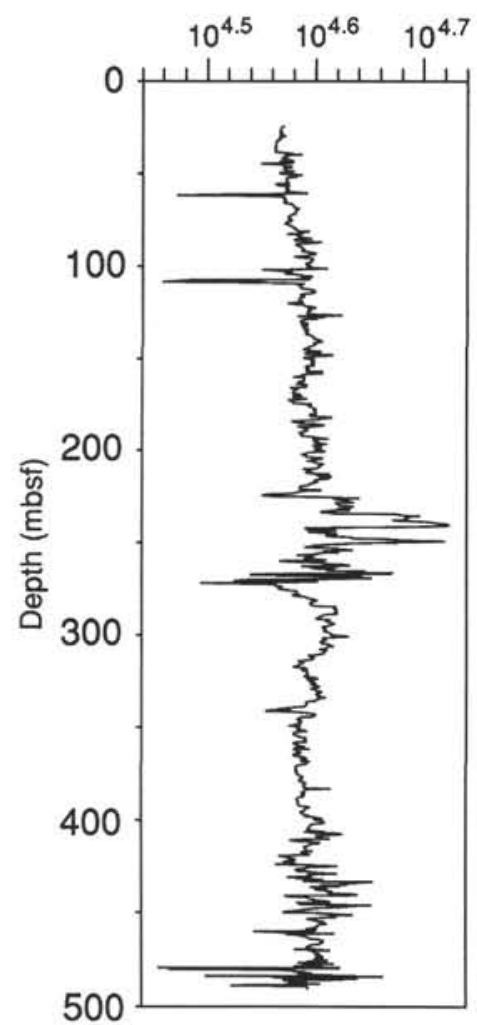

Magnetization

$(\mathrm{A} / \mathrm{m})$

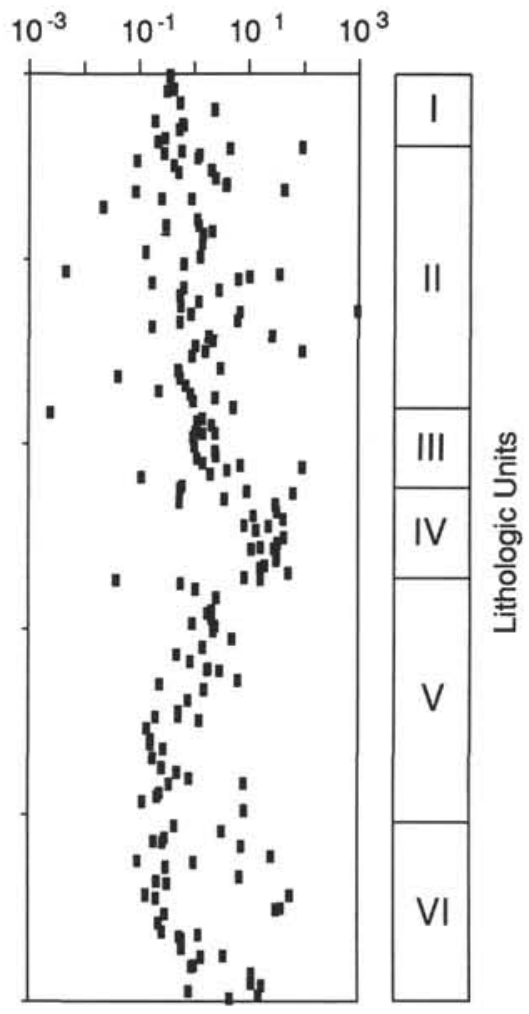

Figure 2. Comparison of downhole measurements of total magnetic field with discrete sample measurements of natural remanent magnetization $\left(J_{0}\right)$. For comparison, both data sets are plotted on a log scale. Lithologic units defined by the shipboard scientists are plotted vs. depth on the right.

hole, and (3) a discussion of the errors associated with the magnetic logging data.

\section{Unit I}

Lithologic Unit I consists of foliated metagabbros, which are the most deformed rocks in the drilled section. This unit extends from the top of the drilled section to 40 meters below seafloor (mbsf) and is characterized by a mean total magnetic field of $35,170 \mathrm{nT}$, and a mean susceptibility of $1.4 \times 10^{-3} \mathrm{SI}$ units, over this depth interval. The peak-to-peak signal amplitude in both logs is small compared to the lower units, suggesting that little change in magnetic properties occurs as a function of depth within this unit. Another factor contributing to the low signal amplitude is the larger diameter in this portion of the hole. During drilling, the bit size was changed at approximately 39.4 mbsf. The caliper log recorded a change in hole diameter at this depth from approximately 30 to $25 \mathrm{~cm}$ (see Goldberg et al., this volume).

Magnetic logs are compared to discrete sample data in Figures 2 and 3. Although only a few samples were taken from this unit, clearly the minicore values of magnetization and magnetic susceptibility, like the logging records, have a relatively low degree of scatter. Arithmetic means of $J_{0}$ and $\chi$ are $0.72 \mathrm{~A} / \mathrm{m}$ and $6.2 \times 10^{-3} \mathrm{SI}$ units, respectively-the lowest values observed within the drill hole.

\section{Unit II}

Lithologic Unit II extends from 39.5 to 180 mbsf and consists primarily of massive olivine and olivine-bearing gabbro. Mean magnetic field and logged susceptibility values over this depth were observed to increase, compared with those of Unit I, to $36,641 \mathrm{nT}$ and $5.4 \times 10^{-3}$ SI units, respectively. Both of these logging records also exhibit a distinct increase in signal amplitude, compared with that of Unit I, and a steady linear increase of $3000 \mathrm{nT}$ was observed in the mean magnetic field between 40 and $160 \mathrm{mbsf}$ (see Fig. 1). At approximately $60 \mathrm{mbsf}$, a peak in the magnetic field can be seen, and a sharp peak in both records occurs at 110 mbsf. These peaks correlate with thin (1 to $3 \mathrm{~cm}$ ) iron and titanium oxide-rich layers described in the core log at this depth (Robinson, Von Herzen, et al., 1989). While the spike at 60 mbsf is marked by only a small amplitude spike in the susceptibility log, this probably results from the different sampling density for the two tools (10 $\mathrm{cm}$ for the UW magnetometer, and $30 \mathrm{~cm}$ for the USGS susceptibility tool).

The mean values of discrete samples for $J_{0}$ and $\chi$ for this unit are $6.5 \mathrm{~A} / \mathrm{m}$ and $26 \times 10^{-3}$ SI units, respectively. In agreement with the logged magnetic field and susceptibility, these parameters show an increase in both scatter and mean value over those of lithologic Unit I. 


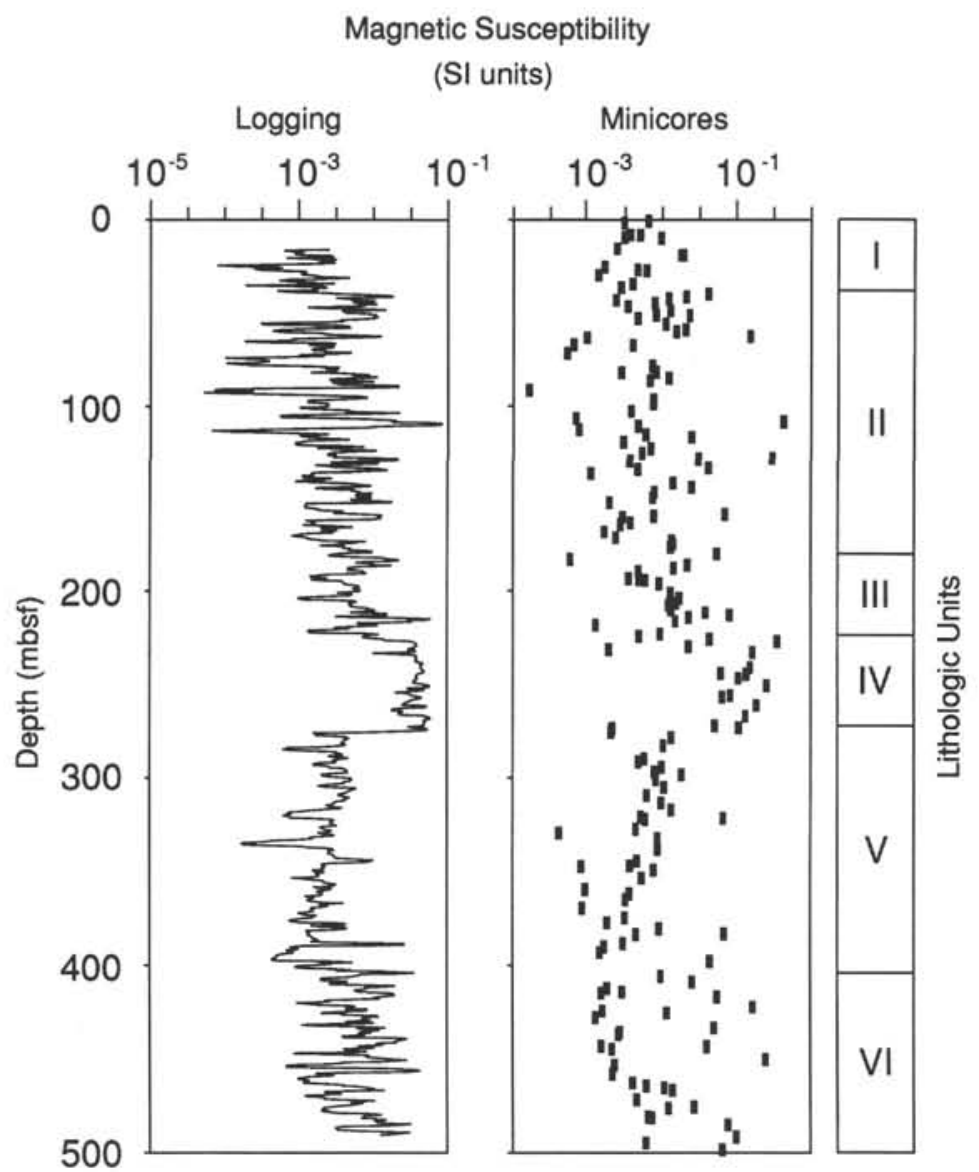

Figure 3. Comparison of downhole measurements of magnetic susceptibility with discrete sample measurements of magnetic susceptibility $\left(\chi_{0}\right)$. For comparison, both data sets are plotted on a log scale. On the right, lithologic units defined by the shipboard scientist are plotted vs. depth.

\section{Unit III}

Lithologic Unit III (180-224 mbsf) consists of olivine gabbro and is distinguished mineralogically from Unit II by an increase in abundance of orthopyroxene, sodic plagioclase, and iron and titanium oxide-rich layers. Despite the change in mineralogy, the magnetic records through this unit display little change in overall signal character from that of Unit II. The mean magnetic field increases slightly, to a value of $37,795 \mathrm{nT}$, and the average susceptibility also increases slightly, to $8.1 \times 10^{-3} \mathrm{SI}$ units. In comparison, mean values of $J_{0}$ and $\chi$ measured for minicores are $6.8 \mathrm{~A} / \mathrm{m}$ and $16 \times 10^{-3} \mathrm{SI}$ units, respectively (see Figs. 2 and 3 ). Like the logged magnetic field, this represents little change from the values determined for Unit II.

Note that there is no apparent change in the overall character of the signal in either log between Units II and III. Rather, in comparison to Units I and V, the record between 39.5 and 224 mbsf contains many small amplitude peaks, and most of these correlate with thin $(1-3 \mathrm{~cm})$ iron and titanium oxide-rich zones described in the petrologic record (Robinson, Von Herzen, et al., 1989). This suggests that Units II and III have the same relative abundance of iron and titanium oxiderich zones because they are magnetically indistinguishable. Although the initial core descriptions described a significant increase in iron and titanium oxide-rich zones in Unit III, it may be that, due to concentration or grain size, this increase is simply more visible in hand sample from Unit III. Alternatively, this may indicate that increased abundance in the iron and titanium oxides occurs, but is dominated by nonmagnetic ilmenite in Unit III.

\section{Unit IV}

A sharp increase in both magnetic field and magnetic susceptibility occurs between 224 and 272 mbsf as a result of the abrupt increase in concentration of primary magnetite within the Unit IV gabbros (see Fig. 1). These highly evolved gabbros contain up to $30 \% \mathrm{FeO}$ and $9 \% \mathrm{TiO}_{2}$ (Shipboard Scientific Party, 1989), and much of this is contained in bands of magnetite and ilmenite that occur interstitially to silicate minerals. Although the average magnetic field within this unit is $40,398 \mathrm{nT}$, peak fields of 50,000 nT were observed. The mean magnetic susceptibility is $37 \times$ $10^{-3} \mathrm{SI}$ units, with peaks ranging up to $80 \times 10^{-3} \mathrm{SI}$ units. An abrupt increase in $J_{0}$ and $\chi$ also was observed in the minicore data in Unit IV (Figs. 2 and 3), and the mean values of these parameters are $26.0 \mathrm{~A} / \mathrm{m}$ and $124 \times 10^{-3} \mathrm{SI}$ units, respectively. While several of the minicores measured from this unit actually ranged higher than the shipboard magnetometer could measure, indicating $J_{0}$ values of $>2500 \mathrm{~A} / \mathrm{m}$, we should mention that paleomagnetic results indicate that the iron and titanium oxiderich gabbros (and many of the other gabbros) have acquired a very strong, but unstable, component of secondary magnetization (drilling remanent magnetization) (Kikawa and Pariso, this volume). The in-situ $J_{0}$ and its stability thus is unknown and, as 
will be discussed later, downhole magnetic data are essential for estimating this parameter.

\section{Unit $V$}

Directly below the magnetite-ilmenite gabbros lies about $110 \mathrm{~m}$ of massive olivine gabbro. This lithologic unit extends from about 272 to 382 mbsf and is characterized by the absence of both deformation and iron-titanium oxides. The uniform mineralogy of this unit is mirrored by a low signal amplitude in both the magnetic susceptibility log and the total magnetic field (mean values are $2.7 \times 10^{-3}$ SI units and 37,572 $\mathrm{nT}$, respectively). Two small peaks occur in both logs at approximately 347 and 393 mbsf; these correlate with isolated magnetite- and ilmenite-rich zones. The overall signal character of Unit V is similar to that of Units II and III, but without the abundant small peaks that characterize the upper units. The mean values of $J_{0}$ and $\chi$ determined from minicores are $2.1 \mathrm{~A} / \mathrm{m}$ and $13 \times 10^{-3}$ SI units, respectively (see Figs. 2 and 3 ). As observed in the logging records, both $J_{0}$ and $\chi$ are characterized by a much lower degree of scatter than is seen in the other lithologic units (with the exception of Unit I), but these parameters have a similar mean value. Although the signal amplitude and scatter remain the same, both the logging records (magnetic field and susceptibility) and the discrete sample data $\left(J_{0}\right.$ and $\left.\chi\right)$ show a decrease in mean value throughout Unit V.

\section{Unit VI}

Unit VI extends from about 382 to 500.5 mbsf and consists primarily of olivine and olivine-rich gabbro, with smaller amounts of troctolite and abundant thin zones rich in irontitanium oxides. In comparison to Unit V, a substantial increase in signal amplitude can be seen in both logging records, but the mean values of the magnetic field and susceptibility increase only slightly $\left(37,713 \mathrm{nT}\right.$ and $8.5 \times 10^{-3}$ SI units, respectively). A higher degree of scatter also was observed in discrete sample data, and the mean values of $J_{0}$ and $X$ increase to $7.6 \mathrm{~A} / \mathrm{m}$ and $31 \times 10^{-3} \mathrm{SI}$ units, respectively. The peaks in the magnetic logs correlate well with the iron and titanium oxide-rich zones and indicate that Unit VI is second only to Unit IV in abundance of iron and titanium oxides.

To summarize, with the exception of the Unit II/Unit III boundary, downhole changes in magnetic field and magnetic susceptibility correlate well with lithologic units described by the shipboard scientists. Figures 4 and 5 show the large-scale changes in these parameters by plotting 10 -m averages of magnetic field and magnetic susceptibility vs. depth. The lowest magnetization and susceptibility values were observed in the upper $40 \mathrm{~m}$ (Unit I). A gradual increase in both parameters occurs from 40 to 224 mbsf (the top of Unit II to the bottom of Unit III). These magnetic data suggest a gradual change in the grain size or an abundance of magnetite in this interval, rather than an abrupt mineralogic change at 180 mbsf, as suggested by the initial core descriptions. Unit IV (224-272 mbsf) has the highest magnetic field and susceptibility observed in the drill hole; this results from the abundance of iron and titanium oxide-rich gabbros. Unit $\mathrm{V}$ (olivine gabbro) is similar to Units II and III in mean value and shows a decrease in mean value with depth. Finally, Unit VI shows an increase in mean value compared to Unit $\mathrm{V}$, which results from an increase in the iron and titanium oxide-rich intervals.

\section{Discrete Samples Compared to Magnetic Logs}

\section{Intensity of Magnetization ( $\left.\mathrm{J}_{0}\right)$ vs. Magnetic Field}

Using forward modeling for a spatially random model, Parker and Daniells (1979) showed that two basic features are required

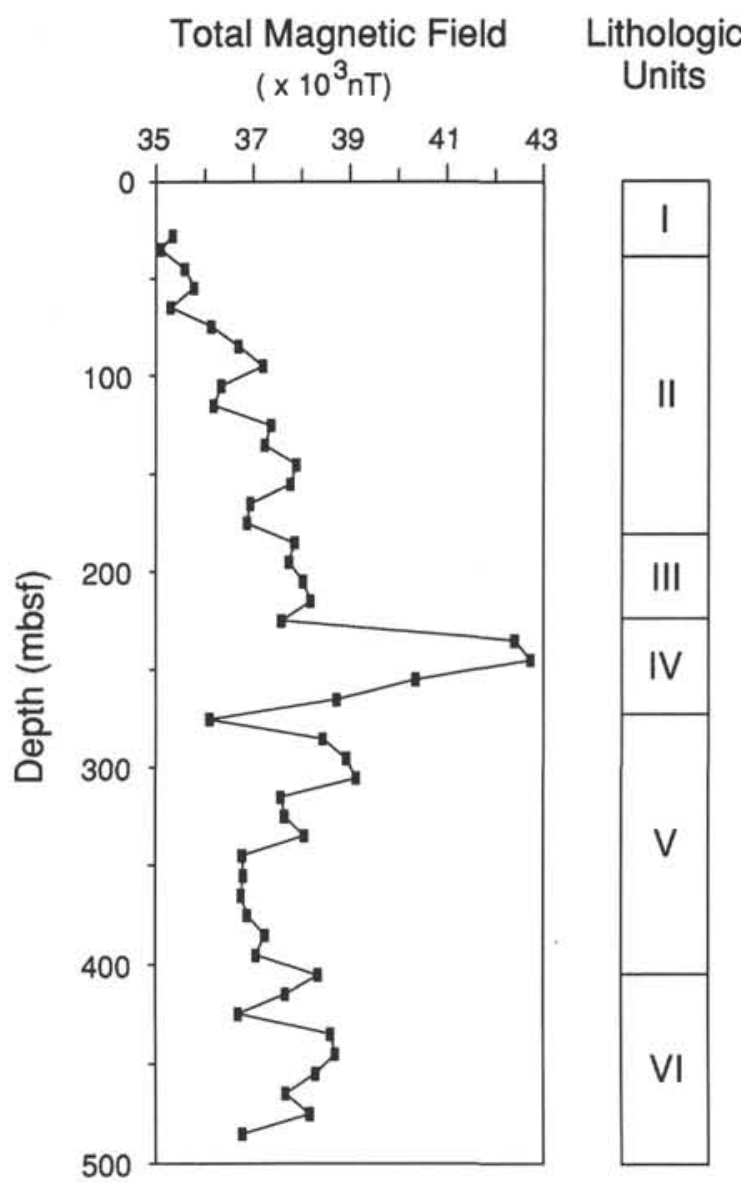

Figure 4. Plot of $10-\mathrm{m}$ averages of downhole magnetic field and lithology vs. depth. With the exception of the Unit II/III boundary, changes in mean magnetic field agree well with the lithologic units defined by the shipboard scientists.

for meaningful interpretation of downhole magnetic data: the medium must have a coherent direction of magnetization (which we will demonstrate later to be true) and the magnetic field must be measured in three vector components. Because both of these criteria are fulfilled by our data, we can compare values of magnetization measured from minicores with the magnetic field measured down the hole. To do this, it is important to understand the nature of the signal in the borehole. During logging, the magnetometer is very near the rock surrounding the borehole $(\sim 12 \mathrm{~cm})$. Each measurement averages a spherical volume that is, at the maximum, the size of several borehole radii. In the absence of instrument noise, a unit that has a perfectly homogeneous remanent magnetization (no change in direction or intensity) will result in a constant value of measured magnetic field in the borehole. The observed signal anomalies are produced only by rock having (1) a sufficiently intense magnetization and (2) significant spatial variations in intensity or direction of magnetization.

To relate measurements of magnetic field made within the borehole to $J_{0}$, essentially two parameters are of interest: changes in the mean of the magnetic field and changes in the peak-to-peak signal amplitude of the magnetic field. While a significant change in the average $I_{\mathrm{nrm}}$ or $J_{0}$ in the rock surrounding the borehole will result in a change in the mean magnetic field, local changes (centimeter-scale) in $J_{0}$ result in an increase in peak-to-peak signal amplitude of the magnetic field. Figure 2 depicts a good correlation between mean value 
Magnetic Susceptibility

(SI units)

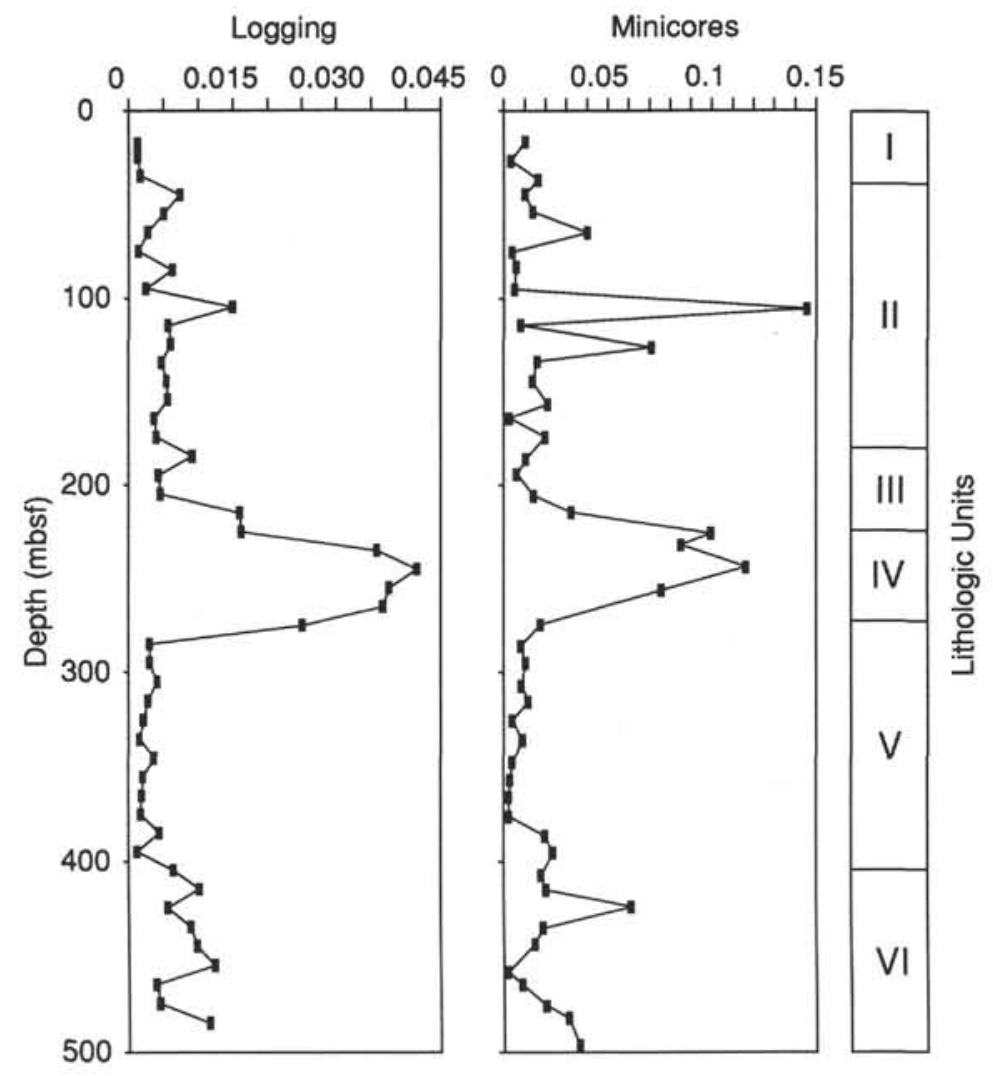

Figure 5. Comparison of $10-\mathrm{m}$ averages of downhole measurements of magnetic susceptibility with $10-\mathrm{m}$ averages of discrete sample measurements of magnetic susceptibility. Data show good agreement in large-scale variation, and with the exception of the Unit II/III bound

and amplitude of the signal in the downhole magnetic log, as well as mean value and scatter observed in the discrete sample data. This illustrates qualitatively that magnetic logs can be used to examine crustal magnetization on two very different scales. Here, we will focus on the large-scale changes that occur on a scale of meters. Small-scale changes, which are represented by peak-to-peak signal amplitude, are the result of small-scale (centimeter-scale) differences in local mineralogy, alteration, or grain size and will be addressed in a later study.

Based upon a model of crustal magnetization that is horizontally uniform (i.e., direction and intensity vary only in the vertical dimension), the average magnetization should be linearly related to the magnetic field observed in the borehole (Bosum et al., 1988; Pariso and Moon, unpubl. data). To test this hypothesis, one must compare the observed magnetic field with the $J_{0}$ determined from minicores. Because the minicore data was sampled at a much lower density than the logging data (roughly 1 sample per $2.8 \mathrm{~m}$, compared with 1 sample per $0.1 \mathrm{~m})$, it is important to chose an averaging window that is large enough to provide a statistically meaningful average. We used an averaging interval of $10 \mathrm{~m}$ for both downhole magnetic field data and for $J_{0}$ determined for minicores. These results are plotted in Figure 6A. While most of these data fall on a linear trend, some data clearly do not. The nonlinearity of some of these data results from two factors. First, many of the Hole 735B gabbros acquired secondary components of magnetization. For the olivine gabbros, this secondary magnetization is usually similar to, or smaller than, the primary magnetization. However, for the iron and titanium oxide-rich gabbros, the secondary components were large, much larger than the proposed in-situ $J_{0}$ values. The $J_{0}$ measured for minicores from these gabbros thus do not reflect the in-situ magnetization and do not correlate with the magnetic field measured in the borehole. Because many of the $10-\mathrm{m}$ averages include iron and titanium oxide-rich gabbros, it is not surprising that some of values will not fall on a linear trend. A second reason for nonlinearity is that the sampling interval for minicores was not uniform. A total of 135 minicores were sampled for an average sampling rate of 1 per $2.8 \mathrm{~m}$. On average, the 10 -m interval will include four $J_{0}$ values, but many intervals will contain fewer samples, and thus the $10-\mathrm{m}$ interval is not always well represented by discrete samples.

Taking these factors into account, we chose a larger, but more subjective, averaging window. We divided the data into 11 discrete sections on the basis of small, but distinct, changes in mean value of total magnetic field and $J_{0}$. The iron and titanium oxide-rich gabbros are represented by one average value (that of Unit IV). Mean values of $J_{0}$ that were calculated for the remaining 10 sections do not include the data from any samples having values lower than $1 \times 10^{-5}$ or higher than $1 \times$ $10^{-2} \mathrm{cgs}$ units (15 samples total). These outliers represent only a small percentage of each unit, but would seriously bias our estimate of the bulk magnetization for the lithologic units if 

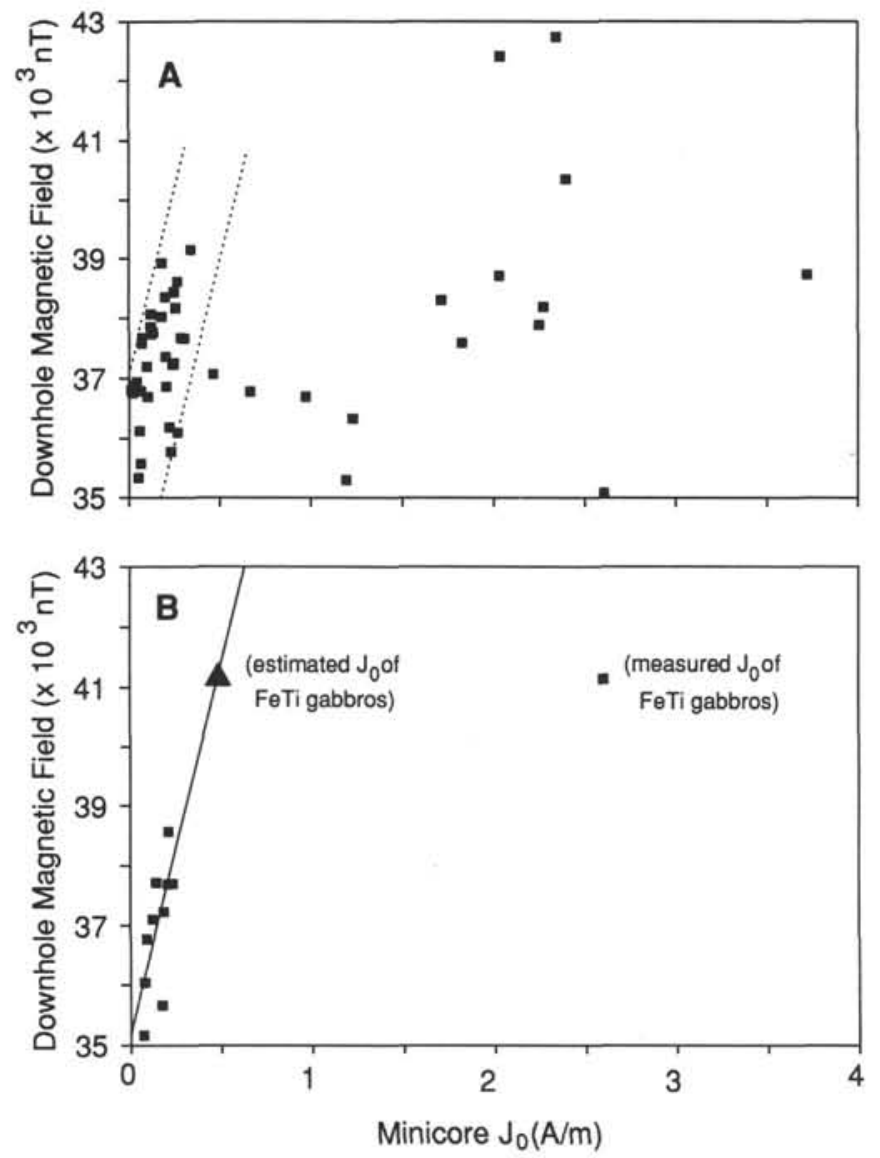

Figure 6. A. Plot of 10-m averages of magnetic field measured in the borehole vs. 10 -m averages of magnetization $\left(J_{0}\right)$ measured on minicore samples. $J_{0}$ values for iron and titanium oxide-rich gabbros (outside the dotted lines) do not agree well with the magnetic field measured in-situ because they acquired large components of secondary magnetization. B. Plot of mean magnetic field measured within the borehole vs. mean magnetization $\left(J_{0}\right)$ measured on minicore samples (squares) for 11 different sections of Hole 735B. In contrast to the other units, the in-situ magnetization of the iron and titanium oxiderich gabbros does not appear to be related linearly to the magnetization measured on the minicores. This is expected because the iron and titanium oxide-rich gabbros have acquired a large component of secondary magnetization during drilling and do not reflect magnetization measured in-situ. To predict the true $J_{0}$ of the iron and titanium oxide-rich gabbros (triangle), a line was fitted to the remaining data (i.e., excluding iron and titanium oxide-rich gabbros) using the least-squares method.

they were included in the calculations. Similarly, we smoothed the magnetic logging data so that the calculated mean is not influenced by sharp peaks within the unit, nor by the high-amplitude anomalies that occur between different lithologic units. Figure $6 \mathrm{~B}$ presents a direct comparison of average values of $J_{0}$ with total magnetic field for these 11 units. As expected, there is a good linear relationship among all of the units, with the exception of the iron and titanium oxide-rich gabbros of Unit IV (224-272 mbsf). We can use the linear relationship between the other units and the total magnetic field value measured in the borehole to estimate the mean $J_{0}$ value of the iron and titanium oxide-rich gabbros. The triangle in Figure $6 \mathrm{~B}$ indicates the projection of the total field value of the iron and titanium oxide-rich gabbros on the linear trend of the other gabbros and also indicates a value of $5 \mathrm{~A} / \mathrm{m}$ for these iron and titanium oxide-rich gabbros. This largescale, linear correlation between the downhole magnetic field and $J_{0}$ reflects changes in the bulk magnetization of this $48-\mathrm{m}$ interval. In all likelihood, there are significant variations about this value.

To estimate the mean $J_{0}$ more accurately, the magnetic susceptibility of the unit should be considered. As we discuss in the next section, the average susceptibility of the iron and titanium oxide-rich gabbros is high $\left(124 \times 10^{-3} \mathrm{SI}\right.$ units). In the presence of Earth's magnetic field, this should induce a component of magnetization (approximately $4 \mathrm{~A} / \mathrm{m}$ ) parallel to the present field. Because this is anti-parallel to the direction of remanent magnetization, the field measured in the borehole represents a net $J_{0}$. Thus, while the effective in-situ magnetization is $5 \mathrm{~A} / \mathrm{m}$, the true $J_{0}$ of the section is probably closer to $9 \mathrm{~A} / \mathrm{m}\left(\right.$ where $J_{\text {net }}=J_{\text {remanent }}+J_{\text {induced }}$, and $\left.J_{\text {induced }}=-4 \mathrm{~A} / \mathrm{m}\right)$. While this value represents an estimated average of the true $J_{0}$ for Unit IV, significant portions of this unit have a higher observed total magnetic field. For example, from 235 to 244 mbsf, the mean of the observed magnetic field is $46,850 \mathrm{nT}$ and, using the previous relationship, this corresponds to an estimated net $J_{0}$ of $10 \mathrm{~A} / \mathrm{m}$ and a true $J_{0}$ of $14 \mathrm{~A} / \mathrm{m}$.

\section{Magnetic Susceptibility}

As observed in Figure 3, susceptibility data of the discrete samples agree well with the borehole data in (1) the trends for the mean value and (2) the degree of scatter. Agreement in the large-scale variation between the two types of measurement is apparent in Figure 5, which shows 10-m averages of magnetic susceptibility plotted vs. depth. As expected, the relationship between logged magnetic susceptibility and the susceptibility of the discrete samples is linear. Figure 7 compares arithmetic means of the two types of measurement for each individual lithologic unit and shows that although actual values differ between the two measurements, they are linearly related. The mean susceptibility of Unit III falls slightly off the trend, but this perhaps is because of the small number of discrete samples within this lithologic unit. A large spike was observed within the Unit III logging data, and this has a significant influence on the calculated value of the mean. However, this thin anomaly is probably not well represented by discrete samples and, therefore, the mean calculated value from the discrete samples is most likely lower than the true mean of Unit III.

The percentage difference between the two susceptibility measurements is not surprising given that the mode of measurement is different. Because minicores were measured using two different types of laboratory susceptibility meters that gave the same values (within $4 \%$ ), we chose to use the laboratory values as the "true" values. A third, hand-held susceptibility meter also was used along the split face of the drill core, and although the results are not presented here, these high-resolution measurements (every $3 \mathrm{~cm}$ ) confirm the accuracy of the laboratory measurements. Thus, we conclude that when the logged values of magnetic susceptibility are corrected to agree with the discrete sample data, they provide useful high-resolution information when studying drilled sections, especially where core recovery is poor.

\section{Magnetic Inclination}

The magnetic inclination calculated from the total magnetic field in the borehole is depicted in Figure 8A. The USGS inclinometers indicated that Hole 735B deviated from vertical, inclined, from $6.5^{\circ}$ near the top of the hole to $3^{\circ}$ at the bottom, toward geographic north; thus, the data have been corrected for this. The total magnetic field in the borehole, which is dominated by Earth's magnetic field, has an average corrected 


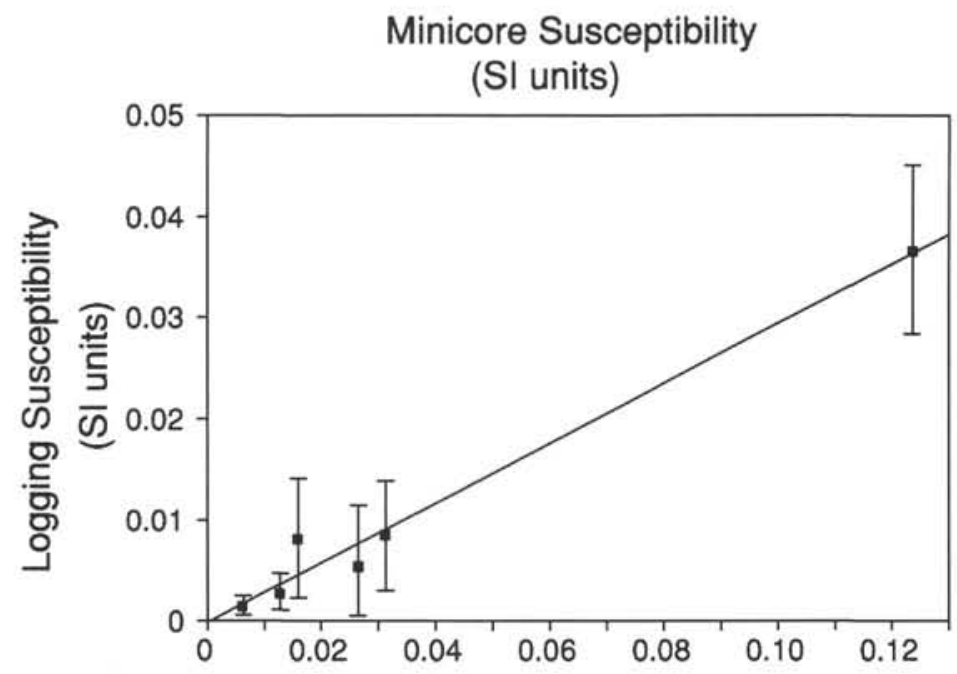

Figure 7. Plot of mean logging magnetic susceptibility values vs. mean minicore susceptibility values for each defined lithologic unit. The line fitted to the data using the least-squares method indicates that logging susceptibility values should be corrected by a factor of 3.4 .

magnetic inclination of $65^{\circ}$. This is slightly steeper than the $61^{\circ}$ predicted by the 1985 IGRF charts for this site and probably results from the small contribution of the remanent magnetization to the magnetic inclination vector. Because of Site 735 's location within reversed magnetic anomaly $5 \mathrm{a}$, the in-situ magnetization should be of reversed polarity (Dick et al., this volume). The addition of a small, reversed component of magnetization (i.e., pointing down and southward) would, in fact, have the effect of steepening the magnetic inclination measured within the borehole. This $4^{\circ}$ steepening requires a minimum contribution of $2600 \mathrm{nT}$ from the rock surrounding the borehole $-\mathrm{a}$ value well within the range of anomaly fields calculated from the observed downhole magnetic field and the ambient magnetic field.

To examine the nature of the contribution of the field produced by the remanent magnetization to the magnetic field measured in-situ, one can examine the vertical field. Expected results using a simple dipole model for both a magnetic reversal and a change in intensity at a Southern Hemisphere site are displayed in Figure 9. One can see that for a polarity change from reversely magnetized rock to normally magnetized rock, the vertical field will experience a change from a negative mean value to a more positive mean value. The degree of positive change is directly related to the strength of the remanent magnetization. For reversely magnetized rocks that increase in magnetic intensity, however, mean values will remain negative and increase in absolute value. The data from Hole $735 \mathrm{~B}$ are displayed in Figure $8 \mathrm{~B}$ and are observed to increase in absolute value in the region of the iron and titanium oxide-rich gabbros. This indicates that, for the bulk of the hole, no polarity changes are present. The small number of narrow, positive spikes are probably caused by large intensity variations over small vertical dimensions.

For comparison with the magnetic logging inclination, the magnetic inclination data for discrete samples are shown in Figures 10A and 10B (see Kikawa and Pariso, this volume, for further discussion). These results show that the inclinations of the natural remanent magnetization $\left(I_{\text {nrm }}\right)$ are split between positive and negative values and have a mean absolute value of $61^{\circ}$. Nearly all stable inclinations $\left(I_{s}\right)$, however, are positive, with a mean value of $65^{\circ} \pm 15^{\circ}$. The

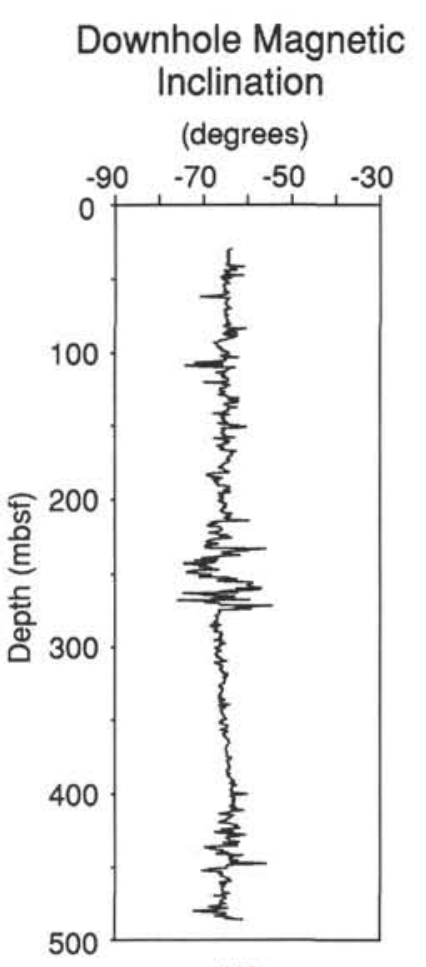

(A)

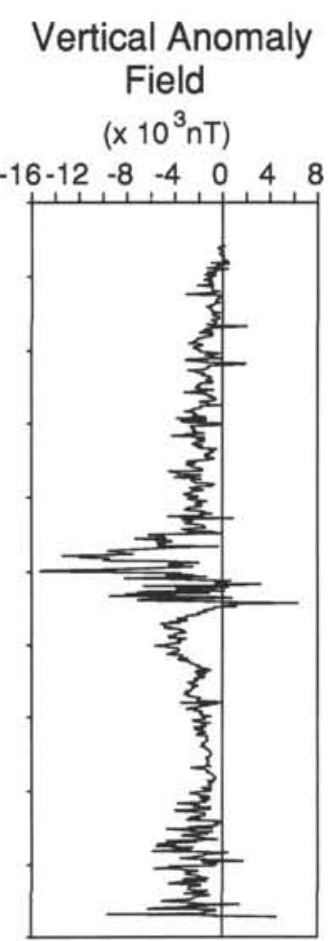

(B)

Figure 8. A. Plot of magnetic inclination (measured with the USGS oriented magnetometer) vs. depth; average $=65^{\circ}$. Inclination within the borehole was determined by finding the arc tangent of the ratio of the vertical to the horizontal magnetic field, and was corrected for the tilt of the drill hole using data from the USGS inclinometers. B. Plot of vertical anomaly field (measured with the USGS oriented magnetometer) vs. depth. The anomaly field was found by subtracting the vertical field caused by the Earth's magnetic field at Site 735 from the observed magnetic field. 


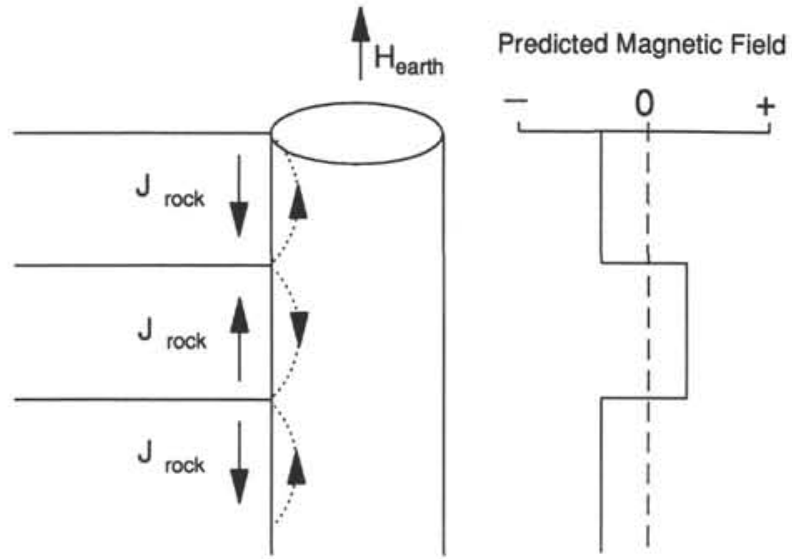

(A)

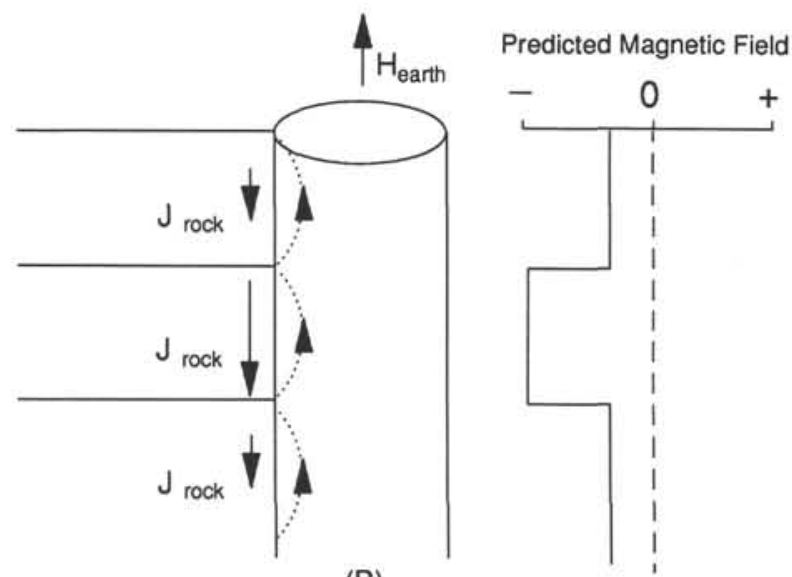

(B)

Figure 9. A. A simple dipole model illustrates the expected change in the vertical magnetic field produced by a zone of normal polarity within a reversely magnetized crustal section. Because Site 735 is located in the Southern Hemisphere, the ambient (Earth's) field has a negative value (pointing upward). A zone of normal magnetization (pointing upward) produces a field in the borehole that points downward. Because this is anti-parallel to the ambient field, it will result in a smaller value of observed magnetic field (in this case, a more positive value). B. A simple dipole model illustrating the expected change in the vertical magnetic field from a zone of high magnetic intensity $\left(J_{0}\right)$ within a crustal section that is reversely magnetized. This zone of higher magnetization is parallel to the ambient magnetic field and results in a larger, more negative value of the magnetic field observed in the borehole.

demagnetization process indicates that the secondary component is soft and easily removed by peak demagnetizing fields of $50 \mathrm{Oe}$ or less. These data, coupled with the analysis of the vertical magnetic field measured downhole, indicate that the in-situ magnetization is all of one polarity (reversed). Further, because the polarity of the in-situ magnetization differs from the stable inclination, these data indicate that the soft secondary component of magnetization was acquired in the direction of the present magnetic field during drilling. Possible sources include a piezo- remanent magnetization caused by the high-pressure shock that drilled samples are subjected to, or an isothermal remanent magnetization that was acquired when the wireline assembly containing the drill core returned to the drilling platform on the ship through the steel drill pipe.

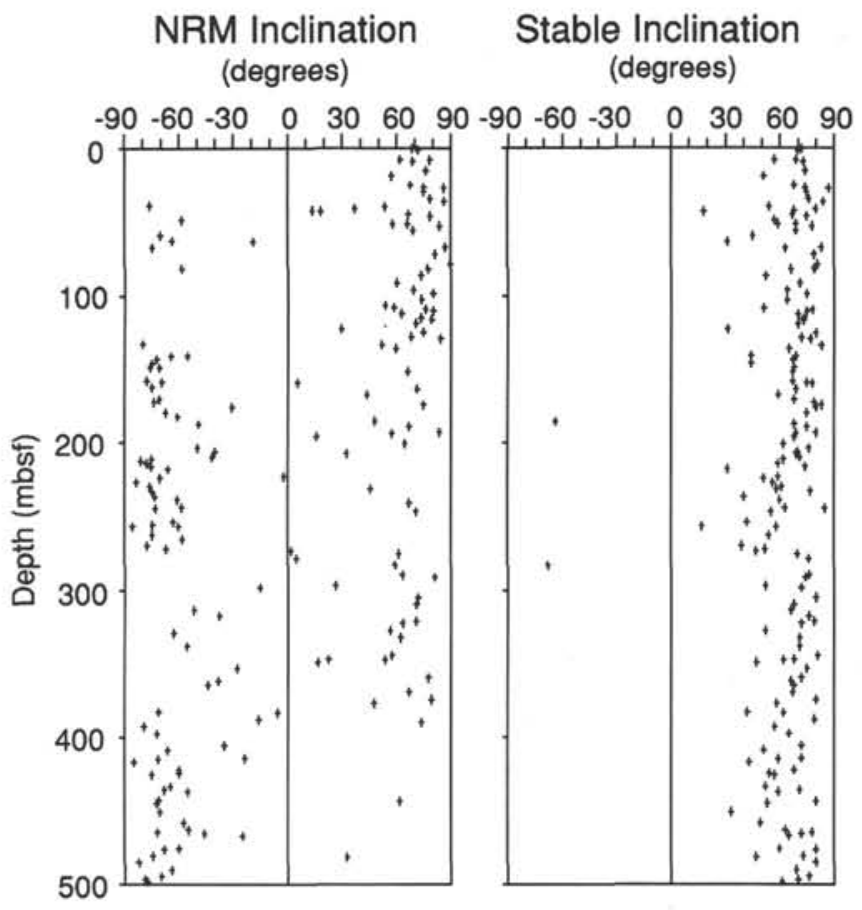

Figure 10. Plots of inclination of natural remanent magnetization $\left(I_{\mathrm{nrm}}\right)$ and stable inclination $\left(I_{\mathrm{s}}\right)$ determined from Hole 735B minicores vs. depth. $I_{\mathrm{nrm}}$ values are split equally between positive and negative and have an average absolute value of $61^{\circ} . I_{\mathrm{s}}$ values are dominated by reversely magnetized samples and average $65^{\circ}$.

\section{Sources of Errors in Logs}

There are several potential sources of error in magnetic logs. These include (1) movement, such as fishtailing, of the tool within the borehole; (2) a borehole that is not perfectly vertical; (3) a borehole that is not perfectly cylindrical; and (4) errors associated with the depth determination. The worse possible case, of course, would be for a tool that is not centralized. Given the dimensions of the UW magnetometer/ susceptibility tool $(8.9 \mathrm{~cm}$ in diameter and $670 \mathrm{~cm}$ long) and the dimensions of the borehole $(25-\mathrm{cm}$ maximum diameter), one might expect a maximum of $2.2^{\circ}$ of fishtailing. Although misalignment of the tool does not affect the total magnetic field measured, it does affect the individual magnetic components. The total magnetic field at Site $735 \mathrm{~B}$ is approximately 37250 $\mathrm{nT}$, this might result in errors as high as $1760 \mathrm{nT}$ when measuring the vertical magnetic field. However, because both of the three-axis magnetometers were centralized, errors from tool movement in the borehole are probably much smaller than this case. Actual errors must be estimated by repeatability among logging tools, as discussed below. Errors resulting from Error 2, (the nonvertical nature of the borehole) are usually corrected using inclinometer measurements. Hole $735 \mathrm{~B}$ was observed to incline from $3.5^{\circ}$ to $6^{\circ}$ from the vertical, and these data thus have been corrected for this.

Errors 3 (noncylindrical borehole) and 4 (inaccurate depth estimates) are difficult to correct quantitatively and are best addressed by checking the repeatability of the logging records and the caliper record. The caliper record shows that few break-outs or other large variations in hole diameter are present (see Goldberg et al., this volume). Figure 11 compares the magnetic field record from a section of Hole 735B for three different logs: (1) the downward-traveling UW magnetometer, (2) the upward-traveling UW magnetometer, and (3) the upward-traveling USGS magnetometer. Although average 
Total Magnetic Field

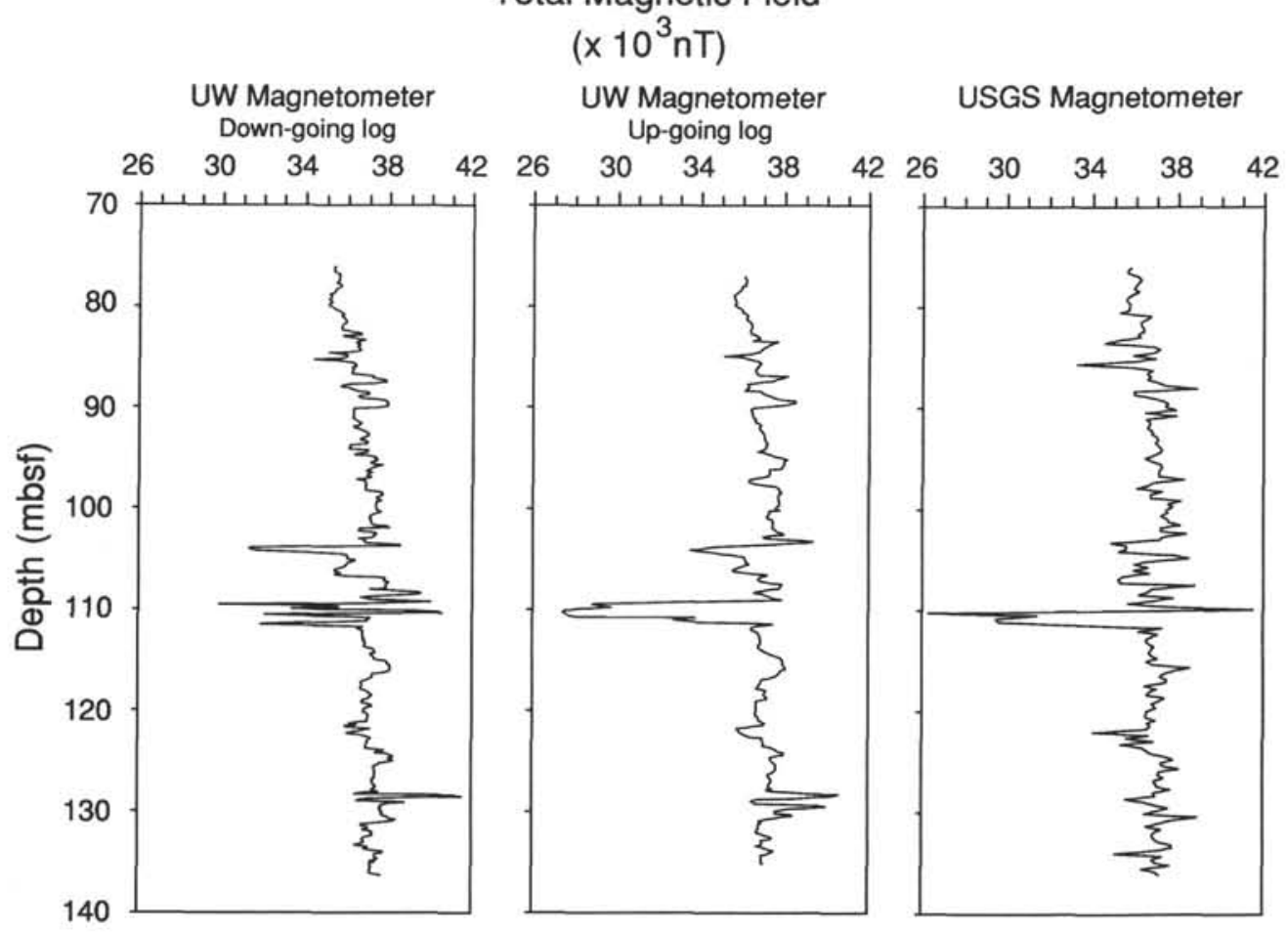

Figure 11. Comparison of downhole magnetic fields from different logging runs. From left to right: downhole magnetic field measured during the downward-traveling log with the UW magnetometer, downhole magnetic field measured during the upward-traveling log with the UW magnetometer, and downhole magnetic field measured during the upward-traveling log with the USGS magnetometer. Although different sampling rates were used during each logging run $(24,12$, and 3 samples $/ \mathrm{m}$, respectively) the major features compare well down to a scale of 2 to $3 \mathrm{~m}$.

sampling densities were different for these three different logs $(24 / \mathrm{m}, 12 / \mathrm{m}$, and $3 / \mathrm{m}$, respectively), the major features of the logs compare well down to a scale of 2 to $3 \mathrm{~m}$. Further, signal anomalies as small as $100 \mathrm{nT}$ can be seen in all three logs. This suggests that errors that would accumulate randomly, such as errors in depth measurement and error from tool movement, are small compared to the observed magnetic anomalies produced by the rock surrounding the borehole.

\section{DISCUSSION}

\section{Magnetic Properties of Oceanic Gabbros}

The high core recovery and continuous penetration of Hole 735B provides us with a well-represented vertical section of oceanic gabbro. Previous studies of gabbro, both dredged from fracture zones and occurring intermittently in DSDP/ ODP drill cores, show a wide variation in magnetic properties, with little indication as to which gabbros are the most representative of oceanic layer 3 (Fox and Opdyke, 1973; Kent et al., 1978; Dunlop and Prevot, 1982). Similarly, Hole 735B gabbros were observed to have a high degree of variation in their magnetic properties: six orders of magnitude of variation were observed in $J_{0}$ and four orders of magnitude of variation were observed in $\chi$. Despite this large range in values, most of the minicore samples $(95 \%)$ fall within two orders of magnitude for both $J_{0}$ and $\chi$, if the iron and titanium oxide-rich gabbros are excluded. While the estimated $J_{0}$ of the iron and titanium oxide-rich gabbros is the highest in the drilled section $(9 \mathrm{~A} / \mathrm{m})$, the bulk of Hole $735 \mathrm{~B}$ gabbros $(425 \mathrm{~m})$ have an average $J_{0}$ of $1.7 \mathrm{~A} / \mathrm{m}$. Similarly, while the iron and titanium oxide-rich gabbros have a high $\chi$, the other gabbros have an average of $16 \times 10^{-3} \mathrm{SI}$ units. The average $Q$ value for the gabbros (excluding the iron and titanium oxide-rich gabbros) is significantly larger than $1(Q=4)$ and indicates the in-situ magnetization in Hole $735 \mathrm{~B}$ is dominated by the natural remanent magnetization. While the iron and titanium oxiderich gabbros are of interest and have high estimated $J_{0}$ values, preliminary rock magnetic work suggests that these gabbros are unable to carry a stable remanent magnetization. The stability of the iron and titanium oxide-rich gabbros is very important and will be addressed in a later study.

In summary, the magnetic properties of the Hole 735B gabbros are consistent with magnetic properties of gabbros that have been previously studied. However, because the Hole 735B crustal section was continuously cored and subject to high-resolution magnetic logging, we now have a much better understanding of the average magnetic properties of the crustal section as a whole. An important, but as yet unanswered, question is whether the Hole 735B gabbros are representative of oceanic layer 3 in general. The geochemical studies and petrologic work (Hebert et al., this volume; Shipboard Scientific Party, 1989) thus far indicate that these gabbros are derived from mid-ocean ridge-type tholeiitic magma. It still is uncertain whether the degree of fractionation observed in Hole 735B gabbros is related to its proximity to the fracture zone. Hole 735B is located approximately $18 \mathrm{~km}$ east of the Atlantis II Fracture Zone. As Dick and et al. (this volume) point out, on the scale of ridge segmentation, the Hole $735 \mathrm{~B}$ crustal section is well away from the fracture zone. This observation together with the geochemical and petrographic results suggest that the Hole 735B gabbros represent "normal" ocean crust. 
Tectonic Rotation of Crustal Blocks

Along Shallow Angle Normal Faults

$\mathrm{N}$

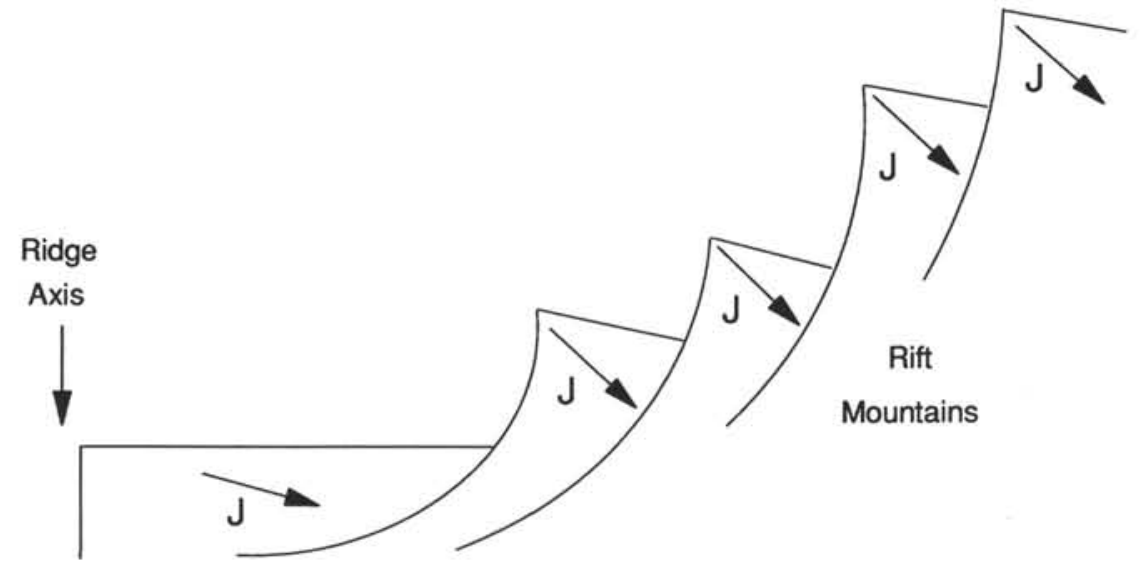

S

Figure 12. This cartoon demonstrates the effect of tectonic rotation upon the direction of the remanent magnetization $(J)$. Crust within the Hole $735 \mathrm{~B}$ section is reversely magnetized and thus at the axis of spreading, the remanent vector points down and to the south. Tectonic rotation of crustal blocks along shallow, inward-facing normal faults would steepen the direction of the remanent magnetization. This is a possible model to explain an average $I_{\text {nrm }}$ value that is higher than predicted by a geocentric axial dipole.

A major difference in the Hole 735B gabbros, compared with previously studied fracture zone gabbros, is the absence of pervasive greenschist metamorphism (Kent et al., 1973; Dunlop and Prevot, 1982). The Hole 735B gabbros have undergone alteration at granulite to lower amphibolite facies and were observed to have few alteration products associated with lower grades of alteration (Stakes et al., this volume). This suggests that the Hole $735 \mathrm{~B}$ crustal section was sealed to hydrothermal alteration at fairly high temperatures. It is possible that fracture zone rocks have a higher initial permeability as a result of the tectonic environment and thus experience these lower grades of metamorphism. In support of this, Dick et al. (this volume) note that rocks dredged from the talus piles within the fracture zone experienced both high grade alteration, as observed in the drill core, and greenschist facies alteration.

Another question arising from this study relates to the abundance of iron and titanium oxide-rich gabbros within layer 3. Although such gabbros have been commonly observed at fracture zones (C. Mevel, pers. comm., 1988), their abundance in "normal" oceanic crust is uncertain. From our data, we can estimate the relative abundance of iron and titanium oxide-rich gabbros in the Hole 735B section. As discussed previously, much of the variation in signal amplitude in the magnetic logs results from zones that are rich in iron and titanium oxides. By simply ranking the lithologic units by signal amplitude, we can compare the relative amount of these iron and titanium oxides in the drilled section. Obviously, Unit IV is almost entirely composed of iron and titanium oxide-rich gabbros. In descending order of relative abundance of iron and titanium oxide-rich zones are Units VI, II-III, V, and I. Units II and III were initially distinguished from each other in core descriptions by an increase in abundance of iron and titanium oxide-rich zones (in Unit III), but magnetic data show little difference in signal amplitude between the two lithologic units. The total abundance of iron and titanium oxide-rich gabbros within the Hole $735 \mathrm{~B}$ crustal section has been roughly estimated from the peaks within the susceptibility log: it is between $15 \%$ and $20 \%$.

\section{Directional Coherence}

The downhole magnetic data, combined with the minicore data, indicate that the bulk of the Hole 735B gabbros have been reversely magnetized and have an average stable inclination of $65^{\circ}$. If corrected for inclination of the borehole, the average inclination increases to $70^{\circ}$. The expected inclination for Site 735B, if one assumes a geocentric axial dipole field, is $52^{\circ}$, which is substantially lower than either the observed or corrected magnetic inclination. This is a slightly larger discrepancy than might be expected for this latitude from secular variations in the geomagnetic field (McFadden and McElhinny, 1984), and this is also a larger discrepancy than could be explained by southward movement of the Hole 735B crustal section after its formation at the ridge crest approximately $11.5 \mathrm{Ma}$. We suggest that the observed steepened inclination is a result of tectonic rotation of the Hole 735B crustal section, although secular variation certainly may have been a contributing factor. Figure 12 depicts a model of tectonic rotation that is consistent with the geologic setting of Site $735 \mathrm{~B}$ and might explain the steeper than expected $I_{\mathrm{nrm}}$ values.

It is of interest to note that although there is substantial plastic deformation observed within the drill core (Cannat, this volume), the crustal section as a whole is coherently magnetized. This suggests that the Hole $735 \mathrm{~B}$ gabbroic section did not experience any relative rotation down the core below the Curie temperature of magnetite (the dominant magnetic mineral). This conclusion is also consistent with the analysis of the metamorphic mineral assemblage, which indicates that the syntectonic deformation that did occur in these gabbros took place well above the Curie temperature (Stakes et al., and Cannat et al., this volume). Finally, attempts to orient the recovered drill core using the paleomagnetic stable declination resulted in a fairly consistent direction of dip of the lineations 
Table 1. Summary of results from two-dimensional, forward modeling of a magnetic reversal in oceanic crust.

\begin{tabular}{ccc}
\hline $\begin{array}{c}\text { Basalt thickness } \\
(\mathrm{km})\end{array}$ & $\begin{array}{c}\text { Gabbros thickness } \\
(\mathrm{km})\end{array}$ & $\begin{array}{c}\text { Contribution of gabbro to } \\
\text { total anomaly field }(\%)\end{array}$ \\
\hline 0.5 & 1.0 & 33 \\
0.5 & 1.5 & 39 \\
0.5 & 2.0 & 45 \\
0.5 & 2.5 & 51 \\
0.5 & 3.0 & 56 \\
1.0 & 1.5 & 20 \\
1.0 & 1.5 & 25 \\
1.0 & 2.0 & 29 \\
1.0 & 2.5 & 35 \\
1.0 & 3.0 & 40 \\
\hline
\end{tabular}

A two-layer model was used; the thickness of each layer was varied within geologically reasonable limits. An average magnetization of 5.0 $\mathrm{A} / \mathrm{m}$ was used for the basalt layer. For the gabbroic layer, the average magnetization of Hole 735B gabbros (excluding the iron and titanium oxide-rich gabbros) was used $(1.7 \mathrm{~A} / \mathrm{m})$.

and foliations observed in the drill core (Cannat and Pariso, this volume), which suggests that the entire Hole 735B crustal section has a single coherent direction of magnetization. The uniform magnetic direction observed throughout Hole 735B is very important because it demonstrates to a first order that oceanic gabbros record the Earth's magnetic field with reasonable fidelity.

\section{Implications for Marine Magnetic Anomalies}

The gabbros recovered from Hole 735B are the first continuously penetrated, vertically oriented samples from oceanic layer 3. As such, these gabbros represent a unique opportunity to examine the average magnetic properties of layer 3 and to study the potential these rocks have for contributing to linear marine magnetic anomalies. Several of the aforementioned studies concluded, based primarily on measurements of $J_{0}$ and of unoriented samples, that gabbros, or specific types of gabbros (e.g., cumulate or isotropic), were capable of contributing, to some degree, to marine magnetic anomalies. Our results indicate that the bulk of the gabbros have a coherent direction of magnetization and a moderate intensity of magnetization and thus confirm these results.

As a quantitative estimate of the relative contribution of gabbro and basalt to marine magnetic anomalies, we have calculated the magnitude of the expected anomalies from a two-dimensional source layer of both basalt and gabbro. We used a value of $5.0 \mathrm{~A} / \mathrm{m}$ for the magnetization of basalt (this is slightly higher than the average value of recovered DSDP basalts, $2.5 \mathrm{~A} / \mathrm{m}$; Lowrie, 1974) and an average value of 1.7 $\mathrm{A} / \mathrm{m}$ for the Hole $735 \mathrm{~B}$ gabbros. The latter is a conservative estimate of the average magnetization of the Hole 735B gabbros because, based on the uncertain magnetic stability, it excludes the iron and titanium oxide-rich gabbros. By varying the thickness of the basalt and gabbro within geologically reasonable limits, we estimated that the gabbroic contribution to marine magnetic anomalies might range from $20 \%$ to $56 \%$ (see Table 1 for complete results and Fig. 13 for an example of the results of this model).

\section{CONCLUSIONS}

Of the six lithologic units in Hole 735B that were defined by the shipboard scientists, five clearly are distinguished by changes in both mean value and signal amplitude of the magnetic field and in magnetic susceptibility values measured downhole. The mineralogic differences between Units II and III appear to be indistinguishable on the basis of magnetic measurements. The downhole magnetic measurements agree

\section{Synthetic Anomaly Profile}
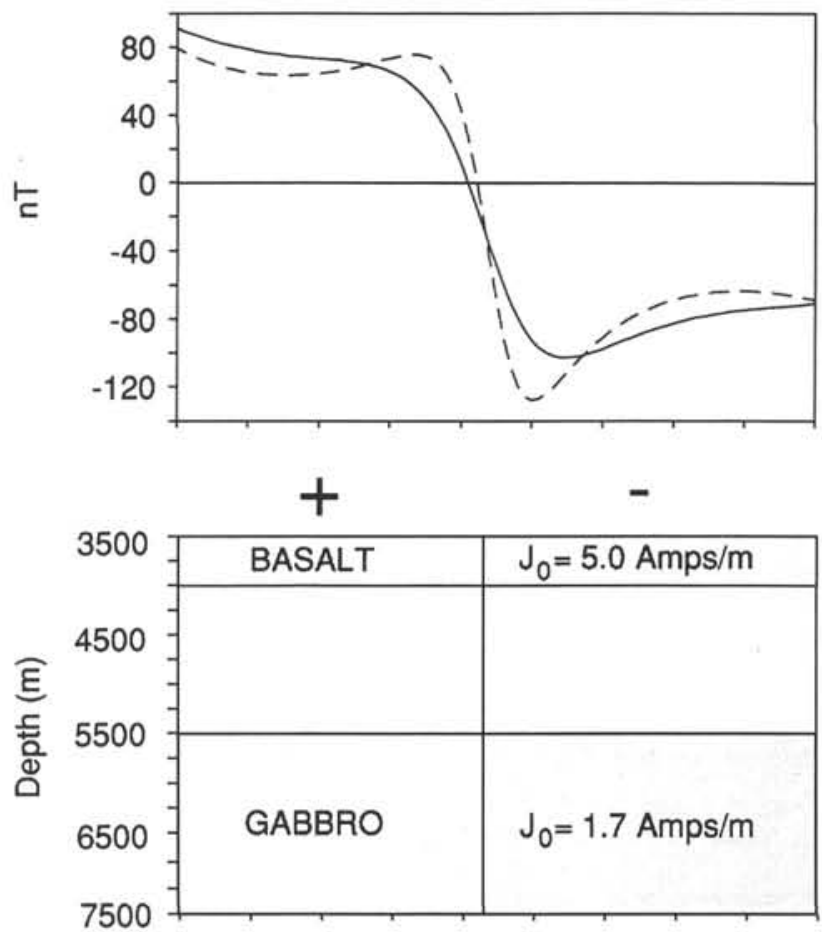

Figure 13. Results from a two-dimensional, forward model of a magnetic reversal in oceanic crust. A two-layer model consisting of basalt and gabbros was used. The possible contribution of the sheeted dikes has not been considered. The solid line is the anomaly expected from a $0.5-\mathrm{km}$ layer of basalt having an average magnetization of 5.0 $\mathrm{A} / \mathrm{m}$. The dashed line is the anomaly expected from a $2.0-\mathrm{km}$ layer of gabbro having an average magnetization $1.7 \mathrm{~A} / \mathrm{m}$. The contribution of the gabbro layer to the total anomaly is $45 \%$, which is a conservative estimate because the iron and titanium oxide-rich gabbros were not included when calculating the average $J_{0}$ of Hole $735 \mathrm{~B}$ gabbros.

well with measurements performed on minicores and allowed us to estimate the average in-situ magnetization of the iron and titanium oxide-rich gabbros at $9 \mathrm{~A} / \mathrm{m}$. The bulk of the Hole $735 \mathrm{~B}$ gabbros (not including the iron and titanium oxide-rich oxide gabbros) have an average $J_{0}$ of $1.7 \mathrm{~A} / \mathrm{m}$, and high $Q$ ratios. The Hole $735 \mathrm{~B}$ crustal section has a single coherent direction of stable magnetization $\left(I_{\mathrm{s}}=65^{\circ}\right)$, indicating that no relative rotation within the drilled section took place below $580^{\circ} \mathrm{C}$ and suggesting that negative NRM inclinations observed in minicore samples are a result of secondary magnetization acquired during drilling itself. Two-dimensional modeling using our magnetic results show that gabbroic layers of oceanic crust can contribute anywhere from $20 \%$ to $56 \%$ and should be considered as an important contributor to linear marine magnetic anomalies.

\section{ACKNOWLEDGMENTS}

We would like to thank the Borehole Research Group at Lamont-Doherty Geological Observatory for their support during Leg 118. In particular, Erich Scholz provided help, advice, and encouragement while developing and testing the UW magnetometer for its initial deployment and David Goldberg provided invaluable help aboard the JOIDES Resolution both prior to and during the logging runs. The manuscript benefitted from reviews by Jeff Fox and two anonymous reviewers. This work was supported by NSF grant OCE- 
8609260 and by the JOI/USSAC fund for post-cruise science support. J. Pariso was supported by a JOI/USSAC Fellowship while this work was completed. This is School of Oceanography contribution 1819 .

\section{REFERENCES}

Atwater, T. M., and Mudie, J. D., 1973. Detailed near-bottom geophysical study of the Gorda Rise. J. Geophys. Res., 78:8665-8686.

Banerjee, S. K., 1980. Magnetism of the oceanic crust: evidence from ophiolite complex. J. Geophys. Res., 85:3557-3566.

Becker, K., Sakai, H., Adamson, Alexandrovich, J., Alt, J. C., Anderson, R. N., Bideau, D., Gable, R., Herzig, P. M., Houghton, S., Ishizuka, H., Kawahata, H., Langseth, A., Lovell, M. A., Malpas, J., Masuda, H., Merrill, R. B., Morin, R. H., Mottle, M. J., Pariso, J. E., Pezard, P., Phillips, J., Sparks, J., Uhlig, S., 1989. Drilling deep into young oceanic crust at Hole 504B , Costa Rica Rift. Rev. Geophys., 27(1):79-103.

Blakely, R. J., 1976. An age-dependent, two-layer model for marine magnetic anomalies. In Sutton, G. H., Maghnani, M. H., Moerly, R. (Eds.), The Geophysics of the Pacific Ocean Basin and Its Margin: City Published (Publisher), 227-234.

Bosum, W., Eberle, D., and Rehli, H.-J., 1988. A gyro-oriented 3component borehole magnetometer for mineral prospecting, with examples of its application. Geophys. Prospect., 36:933-961.

Dunlop, D. J., and Prevot, M., 1982. Magnetic properties and opaque mineralogy of drilled submarine intrusive rocks. Geophys. J.R. Astron. Soc., 69:763-802.

Fox, P. J., and Opdyke, N. D., 1973. Geology of the oceanic crust: magnetic properties of oceanic rocks. J. Geophys. Res., 78:51395154.

Hall, J. M., and Ryall, P.J.C., 1977. Paleomagnetism of basement rocks, Leg 37. In Melson, W., and Aumento, F., et al., Init. Repts. DSDP, 37:489-503.

IGRF, 1985.

Johnson, H. P., 1979. Magnetization of the oceanic crust. Rev. Geophys. Space Phys., 17:215-226.

Johnson, H. P., and Atwater, T., 1977. Magnetic study of basalts from the Mid-Atlantic Ridge, lat., $37^{\circ} \mathrm{N}$. Geol. Soc. Am. Bull., 88:637- 647 .
Johnson, H. P., and Merrill, R. T., 1978. A direct test of the VineMatthews hypothesis. Earth Planet. Sci. Lett., 40:263-269.

Kent, D. V., Honnorez, B. M., Opdyke, N. D., and Fox, P. J., 1978. Magnetic properties of dredged oceanic gabbros and the source of marine magnetic anomalies. Geophys. J. R. Astron. Soc., 55:513537.

Klitgord, K. D., Huestis, S. P., Mudie, J. D., and Parker, R. L., 1975. An analysis of near-bottom magnetic anomalies, seafloor spreading and the magnetized layer. Geophys. J. R. Astron. Soc., $43: 387-424$

Lowrie, W., 1974. Oceanic basalt magnetic properties and the Vine and Matthew hypothesis. J. Geophys. Res., 40:513-536.

McFadden, P. L., and McElhinny, M. W., 1984. A physical model for palaeosecular variation. Geophys. J. R. Astron. Soc., 8:39-50.

Pariso, J. E., and Johnson, H. P., 1989. Magnetic properties of an analog of the lower oceanic crust: magnetic logging and paleomagnetic measurements from drillhole CY-4 in the Troodos Ophiolite. In Cyprus Crustal Study Project: Init. Rept., Hole CY-4, 278-293.

Parker, R. L., and Daniels G. J., 1979. Interpretation of borehole magnetometer data. J. Geophys. Res., 84:5467-5479.

Robinson, P. T., Von Herzen, R. P., et al., 1989. Proc. ODP, Init. Repts., 118: College Station, TX (Ocean Drilling Program).

Smith, G. M., and Banerjee, S. K., 1985. Magnetic properties of plutonic rocks from the Central North Atlantic Ocean. In (Bougault, H., Cande, S. C., et al., Init. Repts. DSDP, 82:Washington (U. S. Govt. Printing Office), 377-383.

Swift, B. A., and Johnson, H. P., 1984. Magnetic properties of the Bay of Islands Ophiolite Suite and implications for the magnetization of oceanic crust. J. Geophys. Res., 89:3291-3308.

Vine, F. J., and Matthews, D. H., 1963. Magnetic anomalies over oceanic ridges. Nature, 199:947-949.

Date of initial receipt: 27 July 1989

Date of acceptance: 5 April 1990

Ms 118B-149 